\title{
How do self-ordered silver nanocrystals influence their growth into triangular single crystals?
}

\author{
A.I . Henry, A.Courty, N.Goubet , and M.P. Pileni ${ }^{1 *}$
}

Laboratoire LM2N, CNRS, UMR 7070, Université P. et M. Curie (Paris VI), BP 524 place Jussieu, 75252 Paris Cedex 05, France

To whom correspondence should be addressed:

e-mail: pileni@sri.jussieu.fr

Figure S1. Bright and Dark field TEM images of triangular silver particles obtained for different experimental conditions. (A) and (B) V=20 $\mu \mathrm{L}, \mathrm{c}=1.610^{11}$ nanocrystals $/ \mu \mathrm{L}, \mathrm{C}$ ) and D) $\mathrm{V}=20 \mu \mathrm{l}, \mathrm{C}=410^{11}$ nanocrystals $/ \mu 1$.

Figure S2. Electron diffraction patterns performed on triangular silver particles on HOPG in the two epitaxial orientations. The dotted and solid hexagons point out the contributions of HOPG and the silver crystal, respectively, and the angular misorientation $\beta$ is represented by the angle between the two straight lines. (A) In the main epitaxial orientation, $\beta=3^{\circ}$. (B) In the second epitaxial orientation, $\beta=3^{\circ}$. 


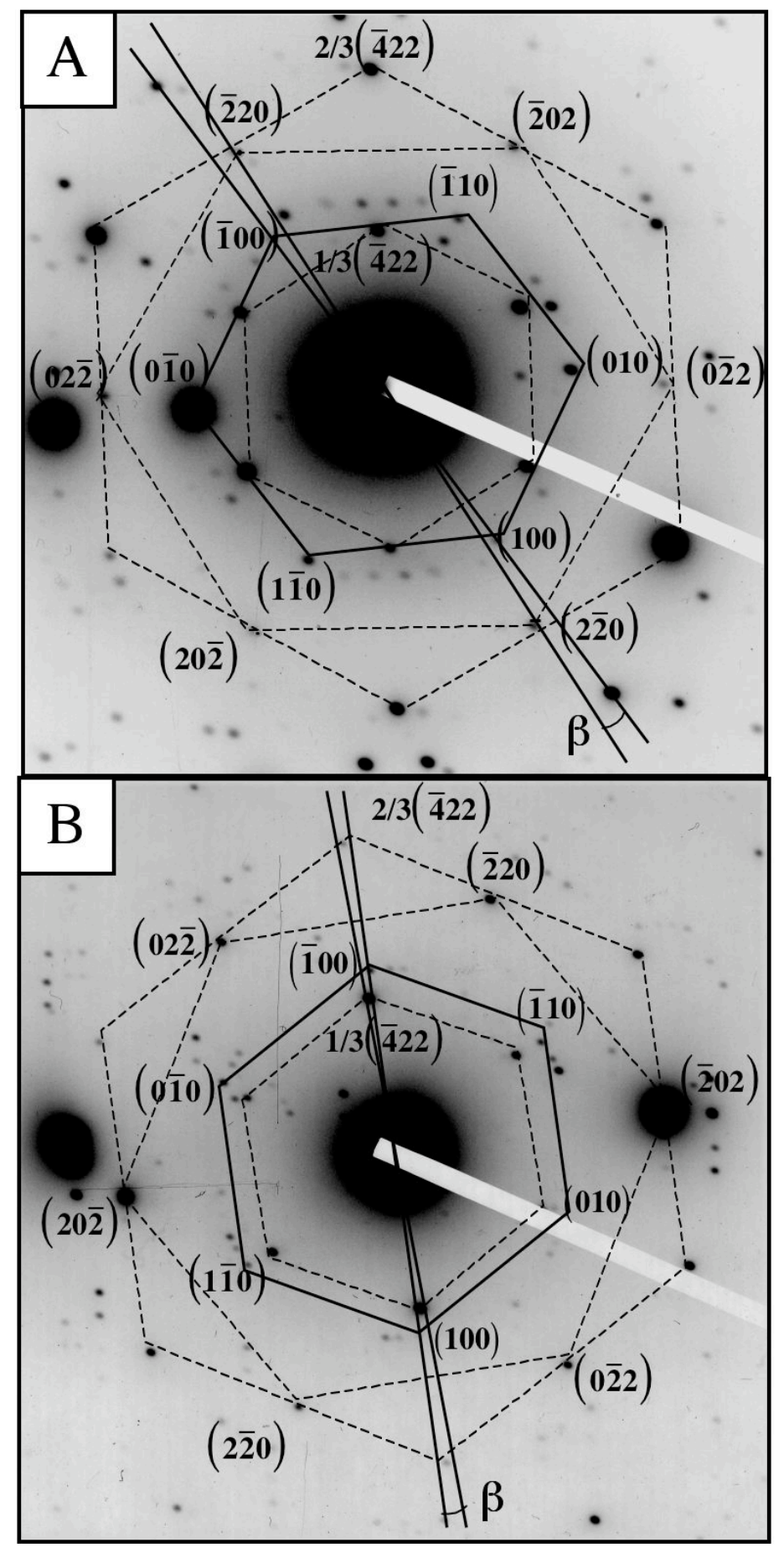

Fig. S1 


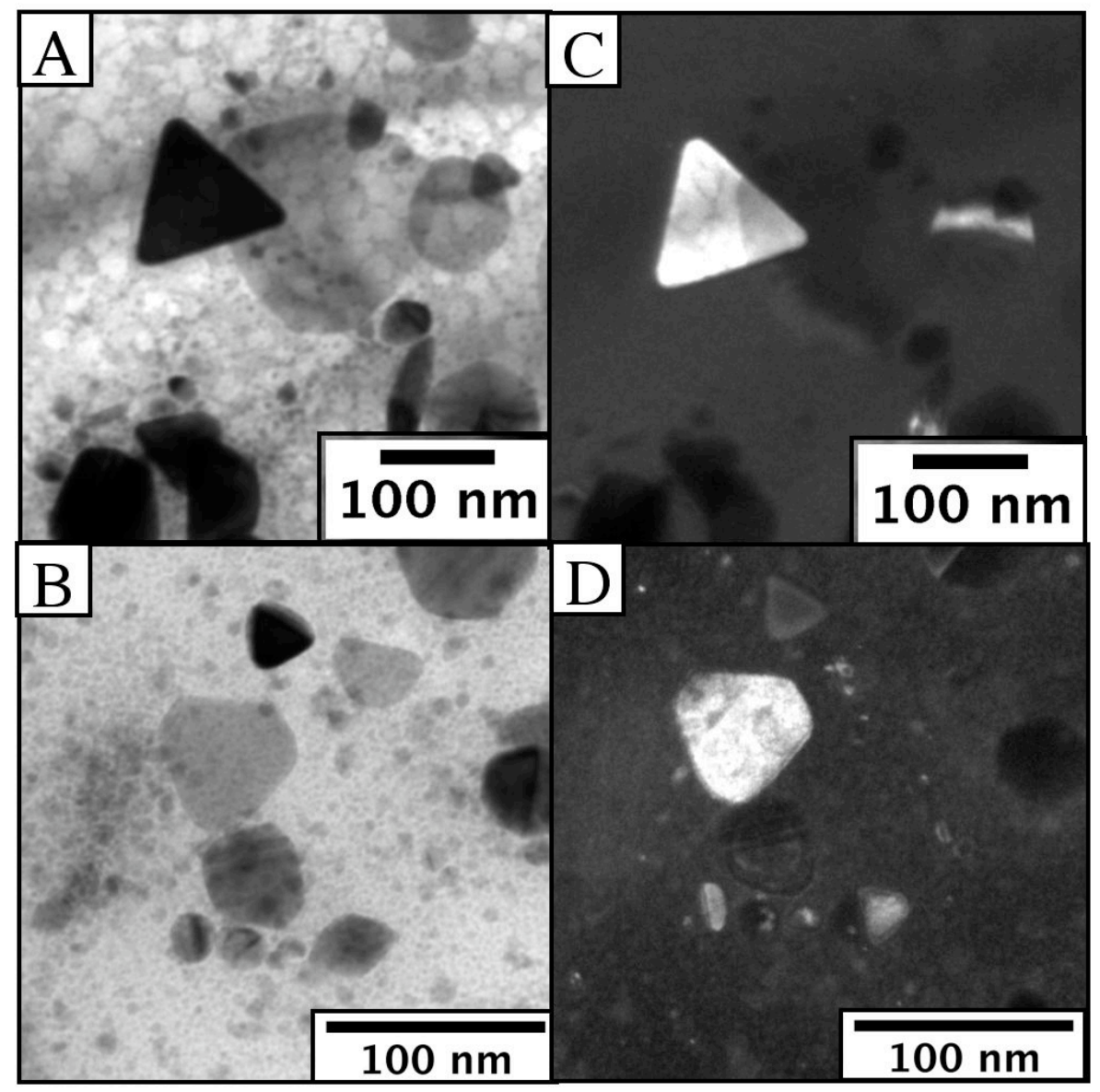

Fig. S2 